\title{
Occurrence of ectopic eruption of different classes of teeth in growing children - A prospective Study
}

\author{
R. Rajashekhar ${ }^{1}$, J. Sharada ${ }^{2}$, K. Suhasini ${ }^{3}$, I. Hemachandrika ${ }^{4}$, Hasanuddin Shaik ${ }^{5}$, P. Tara Singh ${ }^{6 *}$ \\ ${ }^{\mathbf{1}}$ Post Graduate Student, ${ }^{2}$ Professor and HOD, ${ }^{\mathbf{3}}$ Associate Professor, ${ }^{\mathbf{4 - 6}}$ Assistant Professor, ${ }^{\mathbf{1 - 6}}$ Dept. of Pedodontics, ${ }^{\mathbf{1 - 6}}$ Govt. Dental College \\ and Hospital, Hyderabad, Telangana, India
}

\begin{abstract}
Purpose: Most of the disorders related to tooth eruption occur during transitional stage of dentition. Among all the eruption problems, ectopic eruption is said to be the most frequent. This study is undertaken to observe ectopic eruption of different permanent teeth and their relative frequency of occurrence in early mixed dentition stage.

Methods and Materials: After thorough clinical and radiographic examination, a sample of 169 subjects with at least one ectopic permanent tooth in age group of 6-13 years were selected. Data of ectopically erupted teeth was collected and subjected to statistical analysis.

Results: Females are having higher rate of ectopic eruptions when compared to males at a ratio of 2:1.5 and unilateral ectopic eruptions occurred most commonly $(68.2 \%)$.

Conclusion: Ectopic eruption of more than one class of permanent teeth was observed in 1/5th of the subjects. Mandibular lateral incisors are the most commonly ectopically erupted teeth.
\end{abstract}

Keywords: Eruption problems, Ectopic eruption, Permanent teeth.

\section{Introduction}

Tooth eruption process is a complex phenomenon in which various factors act simultaneously for normal eruption. Most of the disorders related to tooth eruption occur during the mixed dentition stage. This process of eruption might be altered by genetic, molecular, cellular, or tissue causes. ${ }^{1}$ Ectopic eruption leads to abnormal position of a tooth. Various etiological factors have been suggested for ectopic eruption viz; morphology of tooth, tooth size-arch length discrepency, presence of supernumerary tooth, rate of deciduous teeth root resorption, injury to developing tooth bud, alteration in eruption sequence, space availability in the arch and rotation of tooth buds. ${ }^{2-4}$ The most frequently found ectopic teeth are maxillary first permanent molars and canines followed by mandibular canines \& second premolars lastly maxillary lateral incisors. ${ }^{5,6}$

The frequency of ectopic eruption are higher in cleft lip $\&$ palate children than in normal children with a prevalence rate of $21.8 \%$ and $4.3 \%$, respectively. On the other hand, in siblings of children with ectopic eruption a prevalence rate was found to be $19.9 \%$, which is much higher than in general population suggesting a genetic cause. ${ }^{7,8}$ This study is undertaken to observe and describe ectopic eruption of different classes of permanent teeth (incisors, canines, and molars) and their relative frequency of occurrence.

\section{Materials and Methods}

In this prospective study a sample of 169 subjects with 61 $(36 \%)$ males \& $108(64 \%)$ females at a ratio of 1.5:2 with ectopic eruption of at least one permanent tooth of age 6-13 years were selected randomly from Department of Pedodontics and Preventive Dentistry, Government Dental
College and Hospital, Hyderabad. Clinical examination was performed with mouth mirror and probe to identify ectopically erupted tooth. Intraoral periapical radiographs (IOPA), Orthopantamogram (OPG) and Study models were evaluated for any supernumerary teeth and for the crown measurements. To find out the possibility of bias due to radiographic magnification, the crown measurements of radiographs were compared with dental casts. The collected data was subjected to statistical analysis using paired ' $t$ ' test (SPSS version 20.0).

\section{Results}

Among all ectopically erupted teeth, lateral incisors were accounting for as high as $49 \%$ \& $39 \%$ in males \& females respectively, which is significant at probability level $<0.05$ (Table 1).

The ectopic eruptions occurred unilaterally in $68.2 \%$ of patients and bilaterally in $31.8 \%$ of patients and it was found statistically significant $(\mathrm{P}<0.05)$. Predominantly, labial or buccal ectopia was seen except mandibular lateral incisors, which presented a lingual location (Table 2).

\section{Discussion}

Ectopic eruption is defined as a condition in which the permanent teeth, because of deficiency of growth in the jaw or segment of jaw, assume a path of eruption that intercepts a primary tooth, causes its premature loss and produces a consequent malposition of the permanent tooth. ${ }^{9}$ Failure to treat ectopic eruption results in loss of arch perimeter, insufficient space for the permanent teeth to erupt thereby resulting in malocclusion. Hence, early diagnosis will help us in preventing a more complicated malocclusion. This

*Corresponding Author: P. Tara Singh, Dept. of Pedodontics, Govt. Dental College and Hospital, Hyderabad, Telangana, India

Email: dr_tara_singh@yahoo.com

http://doi.org/10.18231/j.ijodr.2019.020 
study was done to know the frequency of occurrence of ectopic eruptions of different teeth.

The higher frequency of ectopic eruptions is seen in females when compared to males $(\mathrm{P}<0.05)$. This is not in coincidence with the study done by William ${ }^{10}$ and Young ${ }^{11}$, where males are having more ectopically erupted teeth. This is because of difference in total number of samples i.e. males-174, females -141 , where as in this study males are $61 \&$ females are 108 . When different classes of ectopically erupted teeth among males and females are compared, lateral incisors showed highest frequency of ectopic eruptions accounting for $49 \%$ and $39 \%$ in males and females respectively $(\mathrm{P}<0.05)$.

The order of ectopic eruption observed in this study was mandibular lateral incisors > maxillary central incisors $>$ maxillary canines > maxillary lateral incisors > mandibular central incisors > maxillary first molar > mandibular canines > mandibular first molar. Some of these observations are similar to the study done by William ${ }^{10} \&$ Lewis ${ }^{12}$, but my observations are not in accordance with study done by Sweet ${ }^{13}$ and Nikiforuk. ${ }^{9}$ Their order of ectopic eruptions are mandibular lateral incisors, maxillary first molars, maxillary lateral incisors, mandibular first molars. Ectopic eruption of mandibular lateral incisor \& maxillary central incisor usually occurred unilaterally which is in accordance with the study done by Sweet. ${ }^{13} \mathrm{He}$ also attempted to explain ectopic eruption of permanent central and lateral incisors. Early loss of deciduous canine resulting from ectopic eruption of the permanent lateral incisor was due to insufficient lateral or anteroposterior growth of the jaws. Primary factor was a deficiency in the intensity and time gradients of growth. He also classified ectopic eruption as follows: $:^{13}$

1. Eruption of the maxillary permanent lateral incisor initiating loss of the primary canine

2. Eruption of the maxillary first permanent molar initiating loss of the second primary molar

3. Eruption of mandibular permanent lateral incisors initiating loss of the primary canines

4. Eruption of the mandibular first permanent molar initiating loss of primary second molar

The pedodontist should correlate the dental age with chronological age of each patient for diagnosis of delayed eruption of teeth. The eruption guidance in development of the primary, mixed and permanent dentitions is an integral component of comprehensive oral healthcare for all children. Successful treatment of developing malocclusion after immediate diagnosis can have long term benefits in achieving the goal of occlusal harmony, function and dentofacial esthetics. ${ }^{14}$ Limitations of this study indicate that longitudinal data should be employed in the future with full mouth radiographic surveys and study casts at every 6 months interval from about age 5 until eruption of all permanent teeth under consideration.

\section{Conclusion}

Ectopic eruption of more than one class of permanent tooth was observed in about $1 / 5^{\text {th }}$ of the subjects. The most frequently observed combination was central and lateral incisors with females having higher incidence than males. Mandibular lateral incisors were the most frequently observed ectopically erupted teeth, mandibular first molars had least occurence. Ectopic eruption of individual teeth tend to occur as often bilaterally as unilaterally in the same arch, except for mandibular central incisors, first molars and mandibular canines. Early diagnosis and interception of ectopically erupting teeth will allow us in preventing more complicated malocclusions in future.

\section{Source of Funding}

None.

\section{Conflict of Interest}

None.

\section{References}

1. Barberia-Leache E, Surez-Clua MC, Saavedra-Ontiveros D. Ectopic eruption of the maxillary first permanent molar: characteristics and occurrences in growing children. Angle Orthod 2005;75(4):610-5.

2. Bishara S. Impacted maxillary canines: A review. Am J Orthod Dentofacial Orthop 1992;101:159-71.

3. Peck S, Peck L, Kataja M. Concomitant occurrence of canine malposition \& tooth agenesis: Evidence of orofacial genetic fields. Am J Orthod Dentofacial Orthop 2002;122:608-13.

4. Naser D, Abu Alhaija E, Al khateeb S. Dental age assessment in patients with maxillary canine displacement. Am J Orthod Dentofacial Orthop 2011;140:848-55.

5. Wei ST. Pediatric dentistry: Total patient care. $1^{\text {st }}$ ed. Philadelphia, Pa:Lea and Febiges;1988:462-3.

6. Sim JM. Minor tooth movement in children. $1^{\text {st }}$ ed. Buenos Aires, Argentina: Editorial Mundi;1973:22-4.

7. Carr GE, Mink JR. Ectopic eruption of the Maxillary first permanent molar in cleft lip \& cleft palate children. 1965;32:179-88.

8. Bjerklin K. Ectopic eruption of the maxillary first permanent molar: An epidemiological, familial, etiological \& longitudinal clinical study. Swed Den J Suppl 1994;100:1-16.

9. Nikiforuk G. Ectopic eruption. J Ontario 1948;25:241.

10. O'Meara WF. Ectopic eruption pattern in selected permanent teeth. J Den Res 1962;41(3):607-16.

11. Young DH. Ectopic eruption of permanent first molar. J Dent Child 1957;24:153-62.

12. Lewis SJ. Ectopic eruption of permanent teeth as a factor in premature loss of deciduous teeth. JADA 1936;23:1019.

13. Sweet CA. Ectopic eruption of permanent teeth. JADA 1939;26:574.

14. Kirtaniya BC, Tiwari S, Prakash S, Murmu S and Kumar S."Ectopic Eruption of Teeth and their Management in Children: Literature Review and Case Reports". EC Dent Sci 2018:17(4);409-18.

How to cite this article: Rajashekhar R, Sharada J, Suhasini K, Hemachandrika I, Shaik H, Singh PT. Occurrence of ectopic eruption of different classes of teeth in growing children - A prospective Study, Indian J Orthod Dentofacial Res 2019;5(3):96-7. 